\title{
Rekayasa Perangkat Lunak Pemetaan Perguruan Tinggi Berbasis Web di Kota Tangerang Selatan
}

\author{
Listiyo Arief Nugroho ${ }^{1}$, Viky Ardiansyah ${ }^{2}$, Muhammad Syaiful Arief ${ }^{3}$, Aries Saifudin ${ }^{4}$ \\ ${ }^{1}$ Teknik Informatika, Universitas Pamulang, Tangerang Selatan, Indonesia, 15417 \\ e-mail: 11istiyoan97@gmail.com \\ 2,3,4 Teknik Informatika, Universitas Pamulang, Tangerang Selatan, Indonesia, 15417 \\ e-mail: 2,3,4vikyardiansyah16@gmail.com, ariefbaru22@gmail.com, aries.saifudin@unpam.ac.id
}

Submitted Date: October $02^{\text {nd }}, 2020$

Revised Date: October $10^{\text {th }}, 2020$
Reviewed Date: October $08^{\text {th }}, 2020$

Accepted Date: October 31 ${ }^{\text {st }}, 2020$

\begin{abstract}
Prospective students have the desire to continue their education to universities with faculties and departments that match their interests and talents. Many prospective students do not know the information related to the location of the university or faculty and department available at a university. In general, prospective students find out this information through the university's website or just information from the public. In South Tangerang City, there are already many universities or colleges in the South Tangerang City area. With the disain of the University Mapping WebGIS software in South Tangerang City, it is hoped that the information on universities around South Tangerang City can be easily recieved by prospective students. This software was developed with the Waterfall model, which this development model can make it easier for software developers to observe on planning or analysis before starting the development process. The result of using the Waterfall method is the Mapping College application in South Tangerang City. This mapping application can later be used by prospective students to find information about the location of universities in South Tangerang City or information related to faculties and departments available at a university.
\end{abstract}

Keywords: WebGIS; Mapping; College; Waterfall

\begin{abstract}
Abstrak
Calon mahasiswa memiliki keinginan untuk melanjutkan pendidikan ke universitas dengan fakultas dan jurusan yang sesuai dengan minat dan bakat. Banyak dari calon mahasiswa yang belum mengetahui informasi terkait dengan lokasi universitas atau fakultas dan jurusan yang tersedia pada suatu universitas. Pada umumnya calon mahasiswa mencari tahu informasi tersebut melalui web universitas terkait ataupun hanya sekedar informasi dari masyarakat. Di Kota Tangerang Selatan sudah banyak universitas ataupun perguruan tinggi yang tersebar di daerah Kota Tangerang Selatan. Dengan perancangan perangkat lunak WebGIS Pemetaan Perguruan Tinggi di Kota Tangerang Selatan diharapkan perguruan tinggi yang tersebar di Kota Tangerang Selatan dapat mudah diserap informasinya oleh calon mahasiswa. Perangkat lunak ini dikembangkan dengan model Waterfall, yang mana model pengembangan ini dapat memudahkan pengembang perangkat lunak dengan memperhatikan perencanaan atau analisa sebelum memulai proses pengembangan. Hasil dari penggunaan metode Waterfall adalah aplikasi Pemetaan Perguruaan Tinggi di Kota Tangerang Selatan. Aplikasi pemetaan ini nantinya dapat digunakan oleh calon mahasiswa untuk mencari informasi terkait lokasi universitas di Kota Tangerang Selatan ataupun informasi terkait fakultas dan jurusan yang tersedia di suatu universitas.
\end{abstract}

Kata Kunci: WebGIS; Pemetaan; Perguruan Tinggi; Waterfall 


\section{Pendahuluan}

Sistem pemetaan perguruan tinggi berbasis web adalah sistem yang dapat memberikan informasi geografis atau lokasi perguruan tinggi yang dibutuhkan calon mahasiswa. Selain dapat memberikan informasi geografis sistem pemetaan perguruan tinggi dapat menyediakan informasi perguruan tinggi ataupun universitas. Informasi yang disediakan terdapat informasi umum, fakultas dan jurusan yang tersedia di perguruan tinggi. Sistem pemetaan perguruan tinggi berbasis web merupakan sistem informasi webGIS, Geographic Information System atau yang biasa disingkat GIS alat yang digunakan untuk mengelola data geografis atau spasial, hal ini juga diperkuat dengan kesimpulan Mertha, dkk. (2019) pada jurnalnya tentang implementasi WebGIS pada objek wisata Kota Jakarta Barat cukup efektif. Menurut Annugerah, dkk. (2016) SIG memiliki kemampuan menghubungkan berbagai data pada titik tertentu di bumi yang kemudian dianalisa dan memetakan hasilnya.

Pemetaan saat ini masih sangat sederhana dan umum yang hanya menampilkan lokasi dan informasi biasa seperti alamat universitas, alamat web dan nomor telfon. Pemetaan sekarang juga dibuat untuk umum tidak khusus untuk calon mahasiswa yang membutuhkkan informasi lebih lengkap.

Pada sistem peta yang saat ini masih belum begitu lengkap informasi yang disajikan. Calon mahasiswa yang membutuhkan informasi seperti fakultas, jurusan dan kelas yang tersedia pada suatu perguruan tinggi masih belum dapat diserap informasinya dari sistem pemetaan yang saat ini tersedia.

Pengembangan sistem pemetaan perguruan tinggi di Kota Tangerang Selatan dimaksud untuk membantu calon mahasiswa untuk mendapatkan informasi tentang perguruan tinggi lebih lengkap. Dengan demikian calon mahasiswa tidak perlu membuka banyak web untuk mencari informasi perguruan tinggi yang dituju. Informasi perguruan tinggi akan disajikan dalam satu halaman web agar informasi yang ditampilkan dapat mempermudah pengguna tanpa perlu membuka menu lain.

Pengembangan sistem pemetaan perguruan tinggi menggunakan model waterfall, model waterfall adalah model perancangan sistem secara berurutan. Proses pengembangan yang dilakukan harus berurutan jika proses pertama belum dilakukan maka tidak bisa dilanjutkan ke proses ke dua. Hal ini juga diperkuat dalam jurnal Siswanto, dkk. (2016) bahwa metode waterfall prosesnya harus dilakukan secara berururtan, jika satu proses belum dilakukan maka tidak bisa ke proses selanjutnya. Pengembangan ini akan menggunakan Google Maps API menurut Maharani, dkk. (2017) penggunaan Google Maps API dapat mempermudah visualisasi peta dan mempermudah pencarian alamat.

Pengembangan perangkat lunak ini akan dilakukan dengan beberapa tahapan. Tahap awal yaitu tahap perencanaan, pada tahap ini akan dilakukan untuk menentukan alat pengembangan perangkat lunak, menentukan data, menentukan disain. Tahap kedua yaitu tahap implementasi di mana proses pengembangan dilakukan setelah proses perencanaan diperoleh data yang dapat digunakan untuk melakukan proses pembangunan perangkat lunak. Tahap terakhir adalah tahap percobaan, pada tahap ini perangkat lunak yang sudah dikembangkan akan dilakukan percobaan apakah aplikasi ini sudah layak digunakan atau belum.

\section{Metodologi}

\subsection{Tahap Pengembangan}

Model yang dipilih oleh penulis adalah metodologi waterfall. Dipilihnya metode ini karena dalam implementasinya, sistem pemetaan atau koordinasi merupakan sistem yang membutuhkan validitas data yang tepat agar tidak merugikan pengguna sehingga perlu perancangan dengan model yang tepat sebelum melanjutkan ke tahapan berikutnya. model waterfall yang Metode ini memiliki beberapa tahapan di antaranya:

1. Planning

Pada tahap ini pengembang akan melakukan proses perencanaan pengembangan perangkat lunak. Perencanaan yang dimaksud adalah mencari tahu alat yang akan digunakan dan jenis data seperti apa yang akan dikelola dalam perangkat lunak yang akan dikembangkan.

2. Analisis

Proses analisa terdiri dari analisa kebutuhan pengguna dan analisa kebutuhan perangkat lunak. Analisa kebutuhan berdasarkan hasil dari wawancara dengan pengguna yang layanan, kendala, dan tujuan dari dibuatnya aplikasi.

3. Disain

Tahap ini akan dilakukan proses disain dari perangkat lunak pemetaan perguruan tinggi. Proses ini akan menghasilkan gambaran dari aplikasi pemetaan perguruan tinggi, seperti apa tampilan yang akan ditampilkan ke pengguna. 
4. Implementasi

Tahap ini adalah tahap implementasi di mana dari bentuk disain dikembangkan menggunakan bahasa pemrograman tertentu. Proses ini dilakukan agar dapat dimengerti oleh mesin hingga menjadi sebuah aplikasi yang dapat digunakan sesuai dengan kegunaannya.

5. Pengujian

Pada tahap ini akan dilakukan pengujian yang akan dilakukan pada perangkat lunak yang sudah dikembangkan. Pengujian merupakan bagian utama dari pengembangan software, karena kegagalan pengujian dapat menimbulkan kerugian yang besar (Aziz, Setiawan, Khanh, Nurdiyansyah, \& Yulianti, 2020). Pengujian setiap fungsi dilakukan pengujian untuk memastikan tidak ada kendala pada fungsi aplikasi tersebut untuk memastikan sistem berjalan dengan baik sebelum dikirim ke pengguna.

6. Pemeliharaan

Pada tahap ini sistem sudah berjalan dan digunakan oleh pengguna, penyesuaian biasanya dilakukan setelah ditemukan fungsi yang kurang optimal ataupun tidak bekerja sebagaimana mestinya seperti yang telah dirancangkan. Apabila terdapat kendala pada aplikasi maka akan dilakukan pengecekan pada sistem tersebut.

\subsection{Tahap Planning}

\subsubsection{Analisa Teknis}

Teknologi informasi ditujukan untuk membantu pekerjaan dengan menyediakan informasi dan melakukan berbagai tugas yang berhubungan dengan pengolahan informasi (Hanum \& Saifudin, 2019). Teknologi yang digunakan harus mudah digunakan dan dapat membantu pekerjaan. Teknologi yang akan digunakan menggunakan bahasa pemrograman dan software atau tools pengembangan aplikasi yang umum sehinggan proses integrasi tidak akan sulit. Dengan demikian proses pengembangan bisa berjalan dengan lancar. Proyek pengembangan aplikasi WebGIS ini merupakan proyek proyek kecil, jadi risiko pengembangan ini masih bisa dihindari.

\subsubsection{Analisa Organisasi}

Rencana pengembangan perangkat lunak ini akan menggunakan beberapa tenaga ahli dengan keahlian dibidangnya masing - masing. Untuk mendukung pengembangan perangkat lunak ini akan digunakan beberapa tenaga ahli sebagai berikut:

1. Project Manager

Tugas project manager adalah untuk menghubungi antara klien dan tim pengembang untuk membahas program yang akan dibangun seperti apa sesuai keinginan klien. Project manager juga memiliki tugas untuk merencanakan program dan membuat konsep agar dapat dipahami tim pengembang.

2. Disain UI/UX

Tugas disain adalah untuk menterjemahkan konsep yang diberikan kedalam bentuk gambaran yang nantinya akan dibangun oleh tim programer. Disain yang dibuat diharapkan mudah dimengerti dan digunakan oleh pengguna nantinya.

3. Programmer

Programmer bertugas untuk membangun aplikasi dengan menggunakan bahasa program dengan mengikuti disain yang sudah dibuat agar dapat berfungsi. Bahasa program yang digunakan sesuai dengan kebutuhan dari perangkat lunak itu sendiri.

\subsubsection{Analisa Ekonomi}

Dalam pembuatan project dibutuhkan analisa ekonomi yang nantinya akan berguna sebagai dasar kelayakan project tersebut dapat mendapatkan keuntungan dengan membandingkan pengeluaran. Jika keuntungan didapat lebih tinggi dari pengeluaran pertahunnya maka aplikasi tersebut layak untuk dikembangkan.

Untuk mengetahui kelayakan project ini maka akan dibuat simulasi. Proyek ini dibuatkan untuk instansi pemerintah seperti Dinas Pendidikan dan Kebudayaan dengan pembayaran pengembangan pada awal tahun senilai Rp100.000.000 dan pembayaran pemeliharaan pada tahun - tahun berikutnya Rp75.000.000. Untuk mengetahui biaya awal maka ditentukan harga pembelian lisensi perangkat lunak yang akan digunakan untuk mengembangkan aplikasi pemetaan dengan harga Rp10.000.000 dan biaya tim pengembangan aplikasi dengan nilai Rp50.000.000. Untuk sewa server dan tenaga kerja operasional atau administrator maka dibutuhkan masing - masing Rp8.000.000 dan Rp24.000.000 setiap tahunnya. Untuk lebih detail berikut adalah analisa ekonomi pada gambar. 


Laba Aplikasi
Laba Maintenance
Total Keuntungan
PV Keuntungan
PV dari seluruh keuntungan
Biaya Lisensi Software
Biaya Tenaga Kerja
Total Pengeluaran Pengembangan
Biaya Sewa Server Cloud
Biaya Tenaga Kerja Operasional
Total Pengeluaran Operasional
Total Pengeluaran
PV Pengeluaran
PV dari seluruh Pengeluaran
Total Project Keuntungan - Pengeluaran
NPV Tahunan
Kumulatif NPV
Laba Investasi
Break-Even Point

Break-Even Point (BEP) adalah pendapatan dengan pengeluaran berada pada titik yang sama. Di mana titik total pendapatan dan pengeluaran berada di posisi 0 titik yang berarti pada titik tersebut tidak ada keuntungan ataupun kerugian.

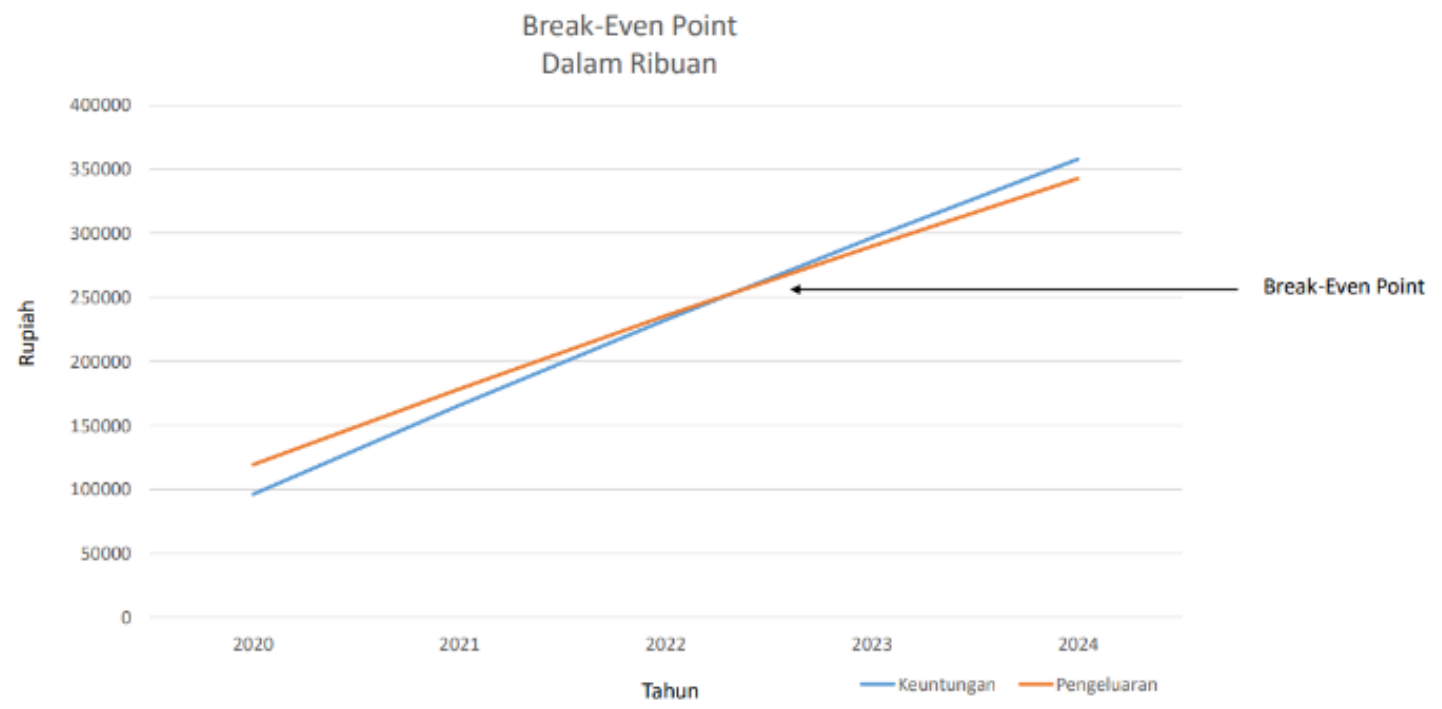

Gambar 2. Grafik Break-Even Point

Dari grafik tersebut dapat dilihat bahwa BEP atau Break-Even Point berada di antara tahun 2022 dengan 2023. Jika dilihat kembali pada Gambar 1 Analisa Ekonomi dapat dilihat bahwa BEP terjadi di tahun ke empat, dari grafik ini bisa diartikan bahwa dalam waktu 3,18 tahun pendapatan sudah bisa melebihi pengeluaran awal. Maka pengembangan bisa dikatakan layak untuk dikembangkan.
Berikut adalah gambar grafik tahun ketahun keuntungan dan pengeluaran untuk project ini.

\subsection{Tahap Analisa}

\subsubsection{Kebutuhan}

Untuk pengembangan aplikasi pemetaan ini dibutuhkan beberapa perangkat yaitu terdiri dari perangkat keras dan perangkat lunak. Untuk perangkat keras yang dibutuhkan adalah notebook atau pc dengan spesifikasi minimal Prosesor Intel i5 generasi ke 7, 4 GB RAM, Hardisk 1 TB. sedangkan untuk perangkat lunak yang akan digunakan dengan OS Windows 10 adalah PostgreSQL sebagai database spasial, PostGIS untuk fitur tambahan PostgreSQL, Ms4w atau Map Server for Windows digunakan sebagai server lokal 
dan browser bisa menggunakan browser Google Chrome, Mozilla Firefox ataupun Microsoft Edge.

\subsubsection{Fungsi}

Pemetaan Perguruan Tinggi di Kota Tangerang Selatan dapat difungsikan sebagai sumber informasi yang dibutuhkan calon mahasiswa untuk mendapatkan informasi tentang lokasi ataupun informasi tentang perguruan tinggi yang dicari. Dengan aplikasi ini calon mahasiswa tidak perlu membuka beberapa web hanya dengan web pemetaan ini calon mahasiswa sudah cukup mendapatkan informasi tentang perguruan tinggi.

\subsubsection{Pengguna}

Pengguna aplikasi ini terbagi menjadi 2 yaitu:

1. Pengguna atau calon mahasiswa adalah pengguna yang akan menggunakan aplikasi tersebut untuk mencari informasi terkait perguruan tinggi atau lokasi perguruan tinggi. Pengguna hanya dapat melakukan melihat informasi dan tidak dapat mengubah informasi apapun yang terdapat pada aplikasi ini.

2. Admin, adalah pengelola yang dapat mengubah informasi pada peta sebaran perguruan tinggi di Kota Tangerang Selatan. Admin memiliki hak untuk mengubah informasi tentang perguruan tinggi yang terdapat pada aplikasi pemetaan.

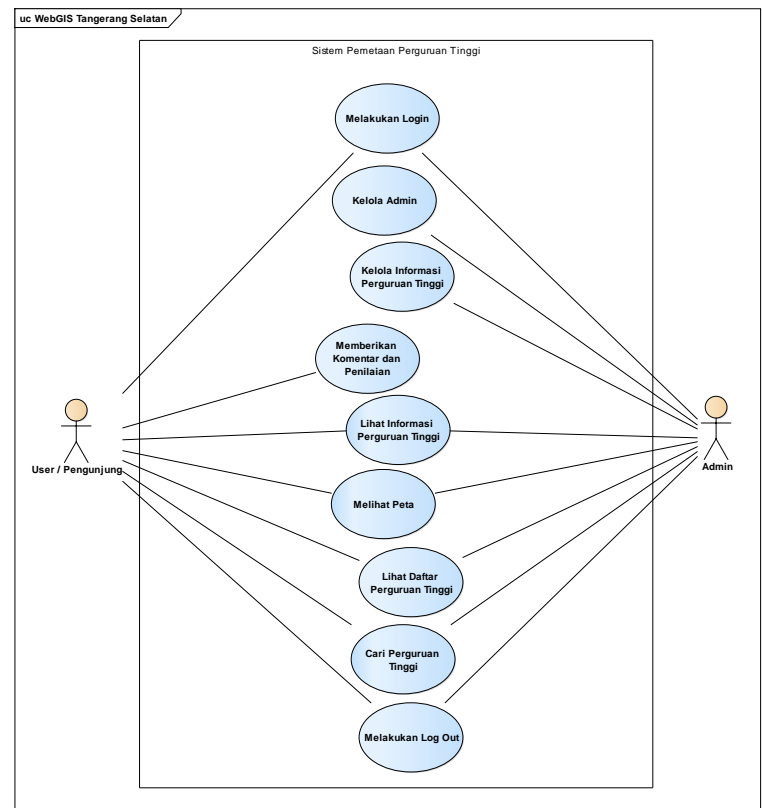

Gambar 3. Diagram Use Case pada Sistem Pemeteaan

\subsubsection{Diagram Use Case}

Use Case diagram adalah ilustrasi atau gambaran dari pengguna yang ditampilkan dalam bentuk interaksi aktor dan sistem atau aplikasi. Diagram ini digunakan untuk mengetahui interaksi apa saja yang akan terjadi pada aplikasi pemetaan agar memperjelas fungsi dari aplikasi itu sendiri. Use case diagram untuk aplikasi yang akan dibuat ditunjukkan pada Gambar 3.

\section{Hasil dan Pembahasan}

\subsection{Database dan Bahasa Pemrograman}

PostgreSQL digunakan sebagai database untuk pengembangan perangkat lunak pemetaan perguruan tinggi. PostgreSQL merupakan alat untuk mengelola masuk dan pengambilan data ke dan dari media penyimpanan. Pengguna menggunakan database ini karena akan menggunakan fitur PostGIS. PostGIS adalah ekstensi dari database PostgreSQL yang fungsinya untuk menambahkan fitur dari database PostgreSQL. Untuk mengelola data spasial maka digunakanlah PostGIS. Database spasial adalah database yang dapat mengelola data spasial, data spasial yang dimaksud adalah data yang berhubungan dengan titik, garis atau poligon yang memiliki kordinat. Database PostgreSQL jika tidak dilengkapi PostGIS maka tidak akan bisa menghasilkan informasi spasial yang seharusnya menjadi informasi utama dari aplikasi ini.

Karena aplikasi yang dikembangkan ini berbasis web maka digunakan bahasa markup HTML. HTML atau Hypertext Markup Language berfungsi untuk membuat dan menyusun web. Untuk mendukung fungsi dari web tersebut maka digunakan bahasa pemrograman PHP. PHP digunakan untuk menghubungkan aplikasi WebGIS ini dengan database.

Google Map API digunakan untuk menghubungkan Google Maps ke aplikasi WebGIS peta sebaran Perguruan Tinggi di Kota Tangerang Selatan. Untuk menghubungkan Google Maps perlu memasukkan script beserta api key yang sudah didapatkan. 


\subsection{Halaman Utama}

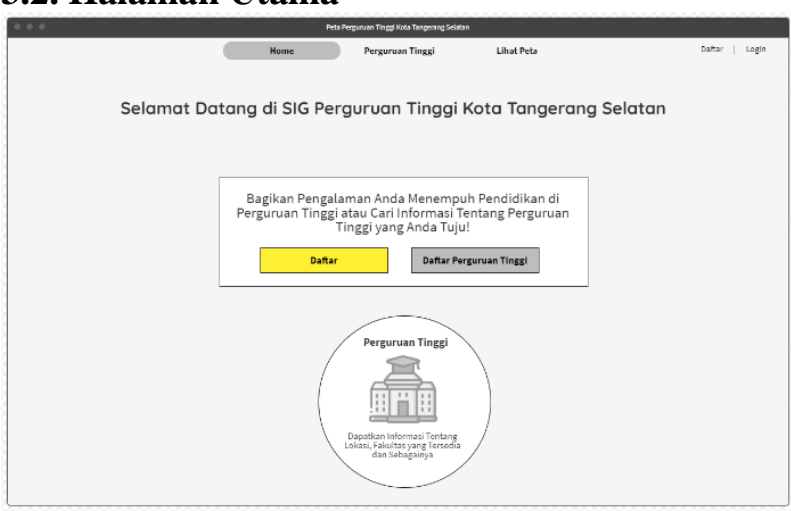

Gambar 4. Halaman Utama

Halaman utama WebGIS perguruan tinggi dapat diakses pengguna maupun admin. Halaman utama menampilkan menu Home, Perguruan Tinggi, Lihat Peta dan Login atau Daftar. Pada menu daftar dapat digunakan oleh pengguna untuk mendaftarkan akun untuk pengguna agar dapat berpartisipasi dalam memasukan informasi kecil pada perguruan tinggi seperti komentar dan penilaian bintang.

Untuk login pada menu tersebut akan terdapat radio button untuk menentukan pengguna atau admin yang akan login ke aplikasi WebGIS. Apabila radio button admin terisi maka akan masuk ke halaman admin. Menu Perguruan Tinggi guna untuk menampilakan daftar Perguruan Tinggi yang tersebar di Kota Tangerang Selatan. Pada Menu Lihat Peta, pengguna atau admin dapat melihat peta sebaran perguruan tinggi di Kota Tangerang Selatan.

\subsection{Halaman Lihat Peta}

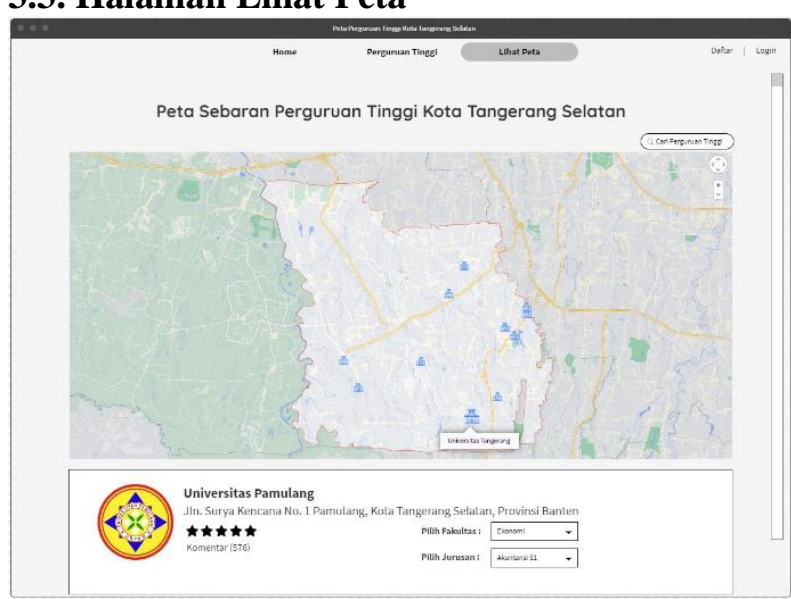

Gambar 5. Halaman Lihat Peta

Halaman Lihat Peta dapat digunakan oleh pengguna untuk melihat informasi perguruan tinggi. Pengguna dapat memilih salah satu perguruan tinggi yang terdapat pada peta. Jika sudah dipilih akan muncul informasi perguruan tinggi tersebut. Pada halaman ini terdapat form pencarian perguruan tinggi yang berguna untuk mencari perguruan tinggi sesuai dengan kata kunci yang dimasukkan.

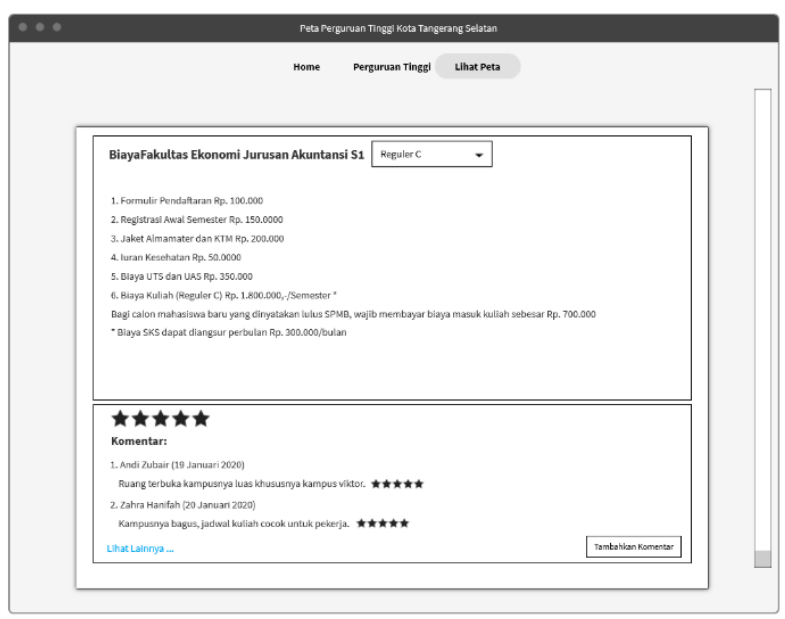

Gambar 6. Halaman Lihat Peta

Informasi yang ditampilkan adalah fakultas dan jurusan yang ada, komentar dan penilaian yang sudah diisi oleh pengguna aplikasi ini. Untuk dapat memasukkan komentar dan penilaian pengguna harus mendaftarkan atau membuat akun. Hal ini dapat memudahkan calon mahasiswa untuk mendapatkan informasi yang dibutuhkan.

\subsection{Halaman Admin}

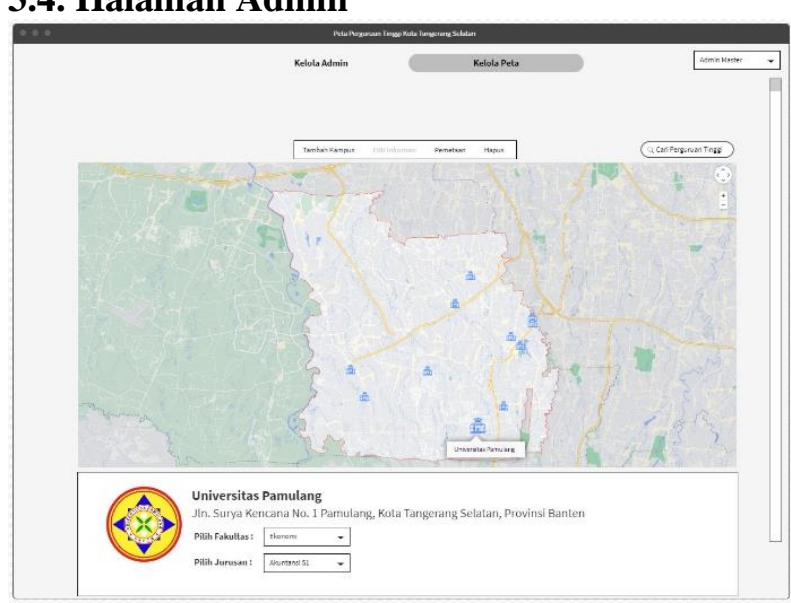

Gambar 7. Halaman Admin

Halaman admin hanya dapat diakses oleh admin. Pada halaman ini admin dapat mengelola peta dan juga admin yang bisa mengakses halaman ini. Pada menu kelola peta, admin dapat menambahkan perguruan tinggi pada peta, mengubah informasi perguruan tinggi, pemetaan 
atau pemindahan tampilan perguruan tinggi pada peta dan penghapusan perguruan tinggi yang sudah ada di peta. Pada menu kelola admin dapat menambahkan dan menghapus akun admin. Akun admin utama dapat mengubah hak admin untuk mengakses halaman admin seperti hak hanya dapat mengubah informasi atau dapat hak keseluruhan terhadap pengelolaan peta.

\section{Kesimpulan}

Hasil dari perancangan aplikasi WebGIS menunjukkan bahwa sistem pemetaan perguruan tinggi Kota Tangerang Selatan dapat memetakan perguruan tinggi. Pemetaan perguruan tinggi Kota Tangerang Selatan dapat memudahkan calon mahasiswa menyerap informasi tentang perguruan tinggi di Kota Tangerang Selatan.

Aplikasi WebGIS dapat membantu calon mahasiswa untuk mendapatkan informasi tentang universitas atau perguruan tinggi. Aplikasi WebGIS dapat menyajikan informasi tentang lokasi universitas dalam bentuk visualisasi peta, informasi tentang fakultas dan jurusan pada universitas tersebut.

\section{Saran}

Oleh karena pesatnya perkembangan teknologi di era digital saat ini, Saran dari penulis adalah mengikuti perkembangan terbaru. Banyak fitur yang bisa dikembangkan lagi dari aplikasi ini seperti mengajak pengguna untuk ikut menyimpan data berupa foto dari tempat yang dikunjungi, ataupun mengirim notifikasi atau pengingat ke perangkat pengguna pada hari-hari khusus, seperti pendaftaran kuliah atau seminar yang berlangsung di universitas tempat pengguna berkuliah. Harapan dari penulis adalah dilakukannya penelitian lebih lanjut dengan penambahan fitur dari teknologi terbaru.

\section{Referensi}

Annugerah, A., Astuti, I. F., \& Kridalaksana, A. H. (2016). Sistem Informasi Geografis Berbasis Web Pemetaan Lokasi Toko Oleh-Oleh Khas Samarinda. Jurnal Informatika Mulawarman Vol. 11, No. 2, 43 - 47.

Ayu, F., \& Permatasari, N. (2018). Perancangan Sistem Informasi Pengolahan Data Praktek Kerja Lapangan (PKL) pada Devisi Humas PT. Pegadaian. Jurnal Intra-Tech, 12 - 26.

Aziz, I. A., Setiawan, B., Khanh, R., Nurdiyansyah, G., \& Yulianti, Y. (2020). Pengujian Black Box pada Aplikasi Sistem Kasir Berbasis Website
Menggunakan Teknik Equivalence Partitions. Jurnal Teknologi Sistem Informasi dan Aplikasi, $\quad 3(2), \quad$ 10.32493/jtsi.v3i2.4693. doi:10.32493/jtsi.v3i2.4693

Maharani, S., Apriani, D., \& Kridalaksana, A. H. (2017). Sistem Informasi Geografis Pemetaan Masjid di Samarinda Berbasis Web. Jurnal Informatika Vol. 11, No. 1, 9-20.

Mertha, I. P., Simadiputra, V., Setyawan, E., \& Suharjito. (2019). Implementasi WebGIS untuk Pemetaan Objek Wisata Kota Jakarta Barat dengan Metode Location Based Service Menggunakan Google Maps API. InfoTekJar : Jurnal Nasional Informatika dan Teknologi Jaringan, 21 - 28.

Pinem, A. P. (2018). Web-Based Mapping untuk Pemetaan Lokasi Kerusakan Jalan Raya Menggunakan Cluster Marker. Jurnal SISFOKOM, Volume 07, Nomor 02, 93 - 97.

Rahmawita, M., \& Afdal, M. (2017). Sistem Informasi Geografis Untuk Pemantauan Penyebaran Tenaga Pengajar. Jurnal Ilmiah Rekayasa dan Manajemen Sistem Informasi, Vol. 3, No. 2, 9 16.

Ruliansyah, B., Muludi, K., \& Febriansyah, F. E. (2016). Pengembangan Sistem Informasi Geografis (SIG) Penyedia Layanan Kesehatan Berbasis Android (Studi Kasus Kota Bandar Lampung). Jurnal Komputasi Vol. 4, No. 1, 99 - 103.

Siswanto, J., \& Jazman, M. (2016). Rancang Bangun WebGIS Pemetaan Lokasi Panti Sosial Menggunakan PMapper. Jurnal Rekayasa dan Manajemen Sistem Informasi, Vol. 2, No. 2, $137-143$.

Sulistyo, R., Erlansari, A., \& Coastera, F. F. (2017). Aplikasi Cloud SQL Berbasis Web. Jurnal Rekusif, Vol. 5, No. 1, 75 - 85.

Usman, A. U., \& Syaechurodji. (2019). Rekayasa Perangkat Lunak Sistem Informasi Geografis (SIG) Tata Letak Penyedia Sarana Penanggulangan Kebakaran. Jurnal SIMIKA Vol. 2 No. 1, 81 - 90. 